\title{
Processing and Properties of Natural Fiber-Reinforced Polymer Composite
}

\author{
Jyoti Prakash Dhal ${ }^{1}$ and S. C. Mishra ${ }^{2}$ \\ ${ }^{1}$ Department of Chemistry, National Institute of Technology, Rourkela, Odisha 769008, India \\ ${ }^{2}$ Department of Metallurgical \& Materials Engineering, National Institute of Technology, Rourkela, Odisha 769008, India \\ Correspondence should be addressed to Jyoti Prakash Dhal; jyoti84.chem@gmail.com
}

Received 24 November 2012; Accepted 5 December 2012

Academic Editor: Víctor M. Castaño

Copyright (c) 2013 J. P. Dhal and S. C. Mishra. This is an open access article distributed under the Creative Commons Attribution License, which permits unrestricted use, distribution, and reproduction in any medium, provided the original work is properly cited.

\begin{abstract}
A novel low cost polymer composite using brown grass flower broom reinforcement is prepared. The prepared polymer composite has the lowest porosity, homogeneous surface structure, and the greatest interface bonding. From the physico-mechanical characterization such as: hardness measurement, density measurement, void fraction or porosity measurement, and flexural strength measurement, it is found that the prepared composite is of light weight and high strength. Again, from dielectric behaviour of this polymer composite, it is found that this material has an efficiency that is considered as a high valued marketable product. As the composite is made using bio-materials from local resources, its cost is less compared to other polymer composites available today.
\end{abstract}

\section{Introduction}

Natural fiber-reinforced polymer composites have raised great attention and interest among materials scientists and engineers in recent years due to that the composites give a combination of superior mechanical property, dielectric property, and environmental advantages such as renewability and biodegradability. Due to various disadvantages such as: high progressing technologies, rising prices of finite resources, and ecounfriendly, the conventional petroleumbased plastic, glass or carbon fiber materials are compensated by natural/bi-based fibers. These fiber composites are well suited as wood substitutes in the housing and construction sector. Using such natural/biofibers with polymers based on renewable resources will allow many environmental issues to be solved. The various natural fibers such as jute, coir, sisal, pineapple, ramie, bamboo, and banana are used as reinforcement of polymer composite, nowadays [1-12]. In recent years, a number of investigations have been made which prove that the worth of natural fibers against their synthetic counterparts such as glass and/or carbon fiberreinforced polymer composites [13-16].
The potential of fiber-reinforced polymer composites was recognized more than 50 years ago, now they can find their applications in almost every industry including construction, aerospace, automotive, and electronics. Composite materials are increasingly used for dielectric applications, that is, applications that make use of electrically insulating or nearly insulating behaviour. This is because of the need of the electronic industry for dielectric materials in electrical insulation, encapsulation, multilayer ceramic chip, and capacitors and for piezoelectric, ferroelectric, and pyroelectric devices that provide sensing, actuation, and so forth. Development of dielectric material with low dielectric constant $k$ and low dielectric loss is considered to be one of the main issues in high-speed microelectronics. The dielectric constant of any material depends upon the polarizability of its molecules and is determined by different contributions: interfacial, dipole, atomic, and electronic polarizations. Interfacial polarization in the composite influences the dielectric properties at very low frequencies and usually decreases with increasing frequency [17-19].

Developing an efficient and light weight dielectric material with high strength from sustainable resources, such as 


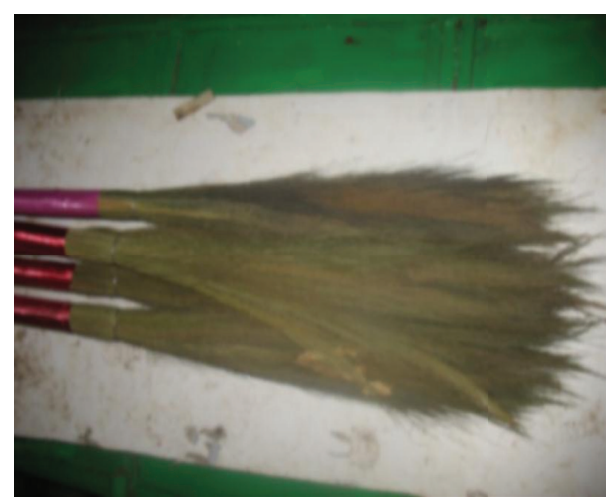

FIGURE 1: Brown grass flower broom.

brown grasses broom fibre, is quite attractive from both application and environmental point of view. This paper aims at development of a biofibre-reinforced polymer composite using natural fibre, that is, brown grass flower broom which is lightweight, commonly available, biodegradable, and low cost. The raw material is commonly available in agricultural sector.

\section{Materials and Methods}

2.1. Materials Used. Epoxy LY 556 (common name: bisphenol A diglycidyl ether) is used as matrix material in the composite fabrication. The hardener used here is HY-951(IUPAC name: $\mathrm{NN}^{\prime}$-bis (2-aminoethylethane-1, 2-diamin). Epoxy Resin and hardeners are mixed in a ratio of $10: 1$ by weight. Brown grass flower broom (shown in Figure 1) is commonly used in house. Short fiber of the broom that is nearly $10 \mathrm{~mm}$ length was prepared and used as the reinforcing agent in the composite preparation.

2.2. Preparation of Test Samples. The biofiber (brown grasses fiber) was mixed with the epoxy by stirring at room temperature, in a glass beaker with the help of suitable glass rod. Hardener was added into the beaker containing mixture at the time of stirring. With proper stirring for 10 minutes, uniform mixing of the reinforcing agent and the polymer matrix were possible. Proper stirring was required for uniform mixing of the reinforcing agent and the polymer matrix and they were poured into suitable moulds to obtain discshaped samples of $12 \mathrm{~mm}$ diameter and $2.5 \mathrm{~mm}$ thickness. Three different broom fiber-reinforced epoxy composites were fabricated varying the amount of reinforcement. Test specimens of suitable dimensions are cut from the composite (shown in Figure 2). The different composites prepared are described in Table 1.

The surface morphology of the sample (Epoxy $+10 \%$ brown grass flower broom) was examined with JEOL T-330 Scanning Electron Microscope. Samples were coated with $60 \AA$ thick platinum in JEOL sputter ion coater for surface conductivity and then observed under SEM, operated at an acceleration voltage of $20.0 \mathrm{kV}$. Hardness test was conducted in a Vickers hardness tester, Leitz, Germany. The Vickers

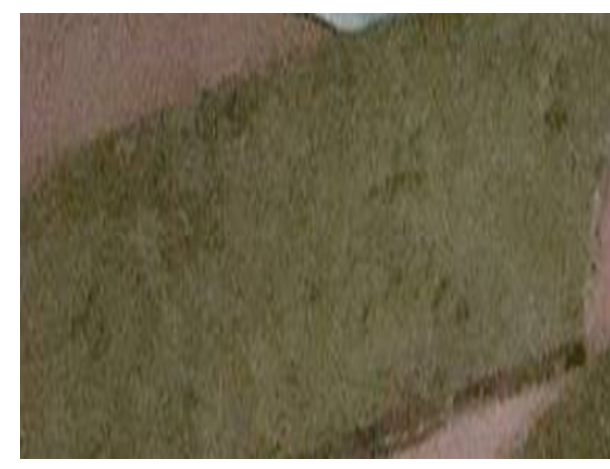

Figure 2: Polymer composites of brown grass flower broom and epoxy.

hardness numbers (VHN) of the hybrid composite were measured under a load of $F=0.3 \mathrm{Kgf}$ and Vickers hardness number was calculated by using the formula:

$$
\begin{aligned}
\mathrm{HV} & =0.1889 \frac{F}{L^{2}}, \\
L & =\frac{X+Y}{2},
\end{aligned}
$$

where $F$ is the applied load, $L$ is the diagonal of square impression $(\mathrm{mm}), X$ is the horizontal length $(\mathrm{mm})$, and $Y$ is the vertical length $(\mathrm{mm})$. The density of neat epoxy and the composites were measured by measuring its mass and volume. The bulk density and void fraction of the composite materials will be obtained from following equations by using Archimedes' principle:

$$
\text { density }=\frac{\text { dry weight }}{\text { soaked weight }- \text { suspended weight }},
$$

void fraction or porocity

$$
=\frac{\text { soaked weight }- \text { dry weight }}{\text { soaked weight }- \text { suspended weight }} \times 100,
$$

where dry weight is the weight of the sample at completely dried condition, soaked weight is the weight of the sample that soaked in kerosene oil, and suspended weight is the weight of the sample suspended in the oil through a string. To evaluate the value of flexural strength (FS), the short-beam shear (SBS) tests (3-point bend test) were performed on the samples at room temperature. The SBS test was conducted as per ASTM D2344-84 using the Instron 1195 UTM. The span length was $40 \mathrm{~mm}$, and the cross head speed was $5 \mathrm{~mm} / \mathrm{min}$. The FS of any composite can be calculated by using the following formula:

$$
\mathrm{FS}=\frac{3 F L}{2 b t^{2}},
$$

where $F$ is the applied load, $L$ is span length, and $t$ and $b$ are the thickness and width of the specimen, respectively.

Dielectric measurements were carried out with the help of a Solartron 1296 Impedance Analyser. For that, the samples 
TABLE 1: Test samples prepared.

\begin{tabular}{lc}
\hline Samples & Compositions \\
\hline Sample A & Pure epoxy \\
Sample B & Epoxy $+10 \%$ brown grass flower broom \\
Sample C & Epoxy $+20 \%$ brown grass flower broom \\
\hline
\end{tabular}

TABLE 2: Variation of density with different weight percent of fiber reinforced in epoxy matrix.

\begin{tabular}{lcc}
\hline Sample & Fiber $(\%)$ & Density $(\mathrm{gm} / \mathrm{cc})$ \\
\hline Sample A & Nil & 1.92 \\
Sample B & 10 & 1.852 \\
Sample C & 20 & 1.614 \\
\hline
\end{tabular}

of the composites had to be cut into thin circular shape, and their surfaces were polished. Then graphite coating was given on their surfaces to make surface conducting and for allowing measurements over frequency interval from $100 \mathrm{~Hz}$ to $1 \mathrm{MHz}$. The dielectric constant and dielectric loss were determined as follows.

$$
\text { Dielectric constant }(k)=\frac{C^{\prime}}{C},
$$

where $C^{\prime}(\mathrm{pF})$ is the measured capacitance, and $C(\mathrm{pF})$ is calculated using the equation

$$
C=\varepsilon_{0}\left(\frac{A}{d}\right)
$$

where $A$ is area of the electrode $\left(\mathrm{mm}^{2}\right)$ and $d$ is the thickness of the sample (mm).

The dielectric loss is given by

$$
\tan \delta=\frac{G(S)}{w C^{\prime}(F)},
$$

where $w=2 \pi f, f$ is the measuring frequency, and $G=$ $G_{0}\left(R-R_{0}\right)[20]$.

\section{Results and Discussion}

The surface morphology of the prepared test sample with $10 \%$ broom fiber is shown in Figure 3. The interface bonding of the broom fiber with epoxy resin is clearly visible. This composite has lowest porosity and homogeneous surface structure.

Hardness values of the samples are given in Figure 4. From the figure, it can be seen that the hardness of broom fiber-reinforced polymer composite is more than that of the pure epoxy and also increases with the increase in amount of reinforcement. The increase in hardness of the composite may be due to stronger interface bonding of the broom fiber with epoxy resin.

The actual density of the composite is determined experimentally by simple water immersion technique by using Archimedes principle. The densities of the samples are given in Table 2. It is observed that the presence of broom fibres

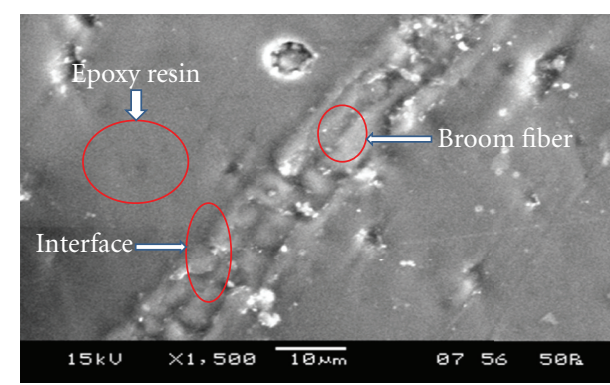

FIGURE 3: Surface morphology of the composite with $10 \%$ of broom fiber reinforcement.

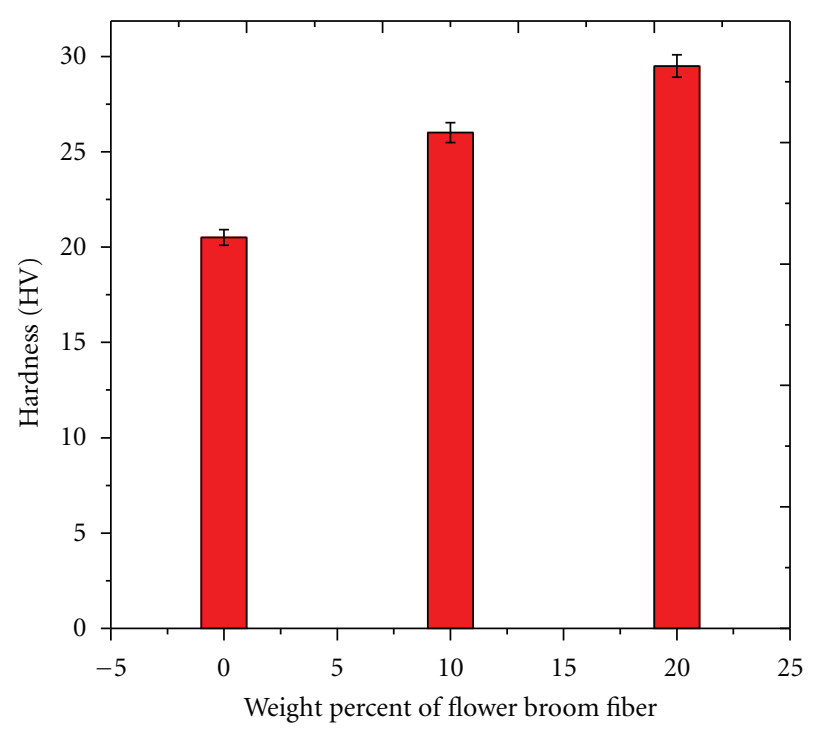

FIGURE 4: Variation of hardness (HV) of composites with weight percent of flower broom fiber-reinforced epoxy composites.

as fillers in epoxy matrix reduces the density of polymer composite and hence makes it lightweight. This may be due to presence of the high air content.

With addition of flower broom fiber in epoxy resin, the volume fraction of voids is increased as shown in Figure 5. The voids significantly affect some of the mechanical properties and even the performance of the composites in the place of use.

Figure 6 shows the comparison of flexural strengths of the flower broom-reinforced epoxy composites. There is an increase in the flexural strength that is associated with an increase in wt\% of short fiber flower broom in composites. This may be due to the presence of stronger interfacial bonds (as shown in SEM figure). Impregnations of natural fibre help in the interface bonding which improve the structural properties of the composite. The micromechanical events that occur for a long fiber-reinforced composite are not the same as those observed for a short fiber reinforced composites. In a short fiber, there are variations in stress distribution along the fiber matrix interface, and end effects can be neglected in the case of long fibers, but they can be very important in the case of short fiber-reinforced composites. 


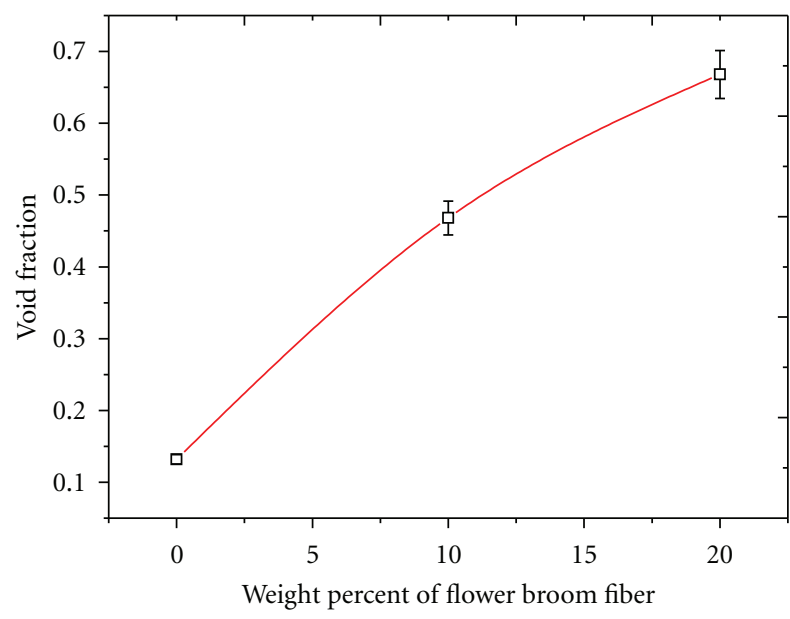

FIGURE 5: Variation of void fraction of composite with weight $\%$ of broom fiber-reinforced epoxy composites.

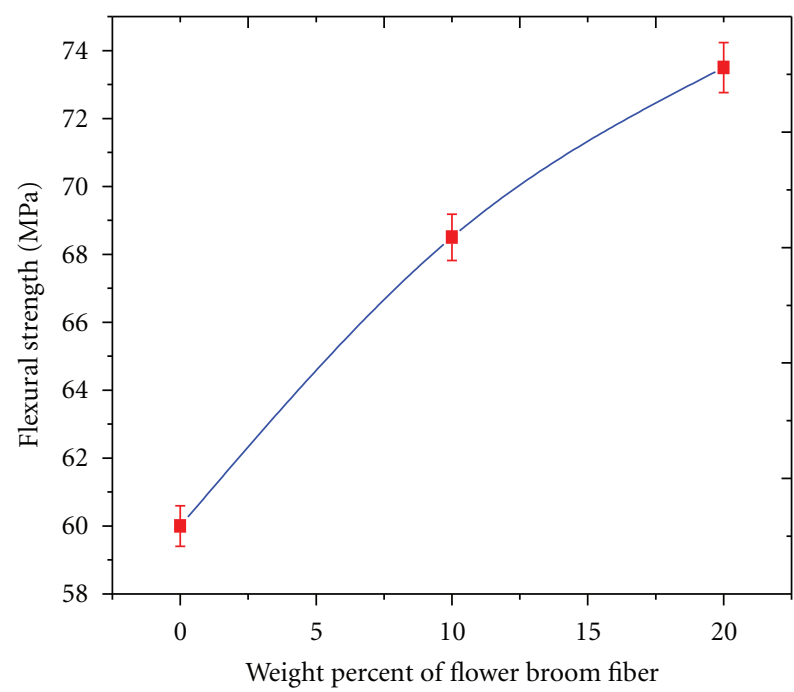

FIgURE 6: Variation of flexural strength of composites with weight percent of flower broom fiber-reinforced epoxy composites.

It is observed from Figure 7 that the dielectric constant (at $100 \mathrm{~Hz}$ frequency) increases with the volume fraction reinforcement. However, from Figures 8 and 9, it is inferred that the dielectric constant and the dielectric loss initially reduce and attain a steady state with an increase in frequency. This may be due to the fact that (i) dielectric behavior is dependent on porosity, (ii) on material properties, and also on (iii) interface bonding in case of composite materials. So in this study the materials used are having many diverse physico-mechanical properties. However, it is found that making a composite with these wastes, using a polymer binder, is best suited for providing good mechanical strength without sacrificing its dielectric property. Impregnation of natural fibre helps in the interface bonding and distribution of absorbed moisture in the material which may be one of the reasons for change in dielectric properties. With increase in frequency, the dielectric constant of the composites decreases

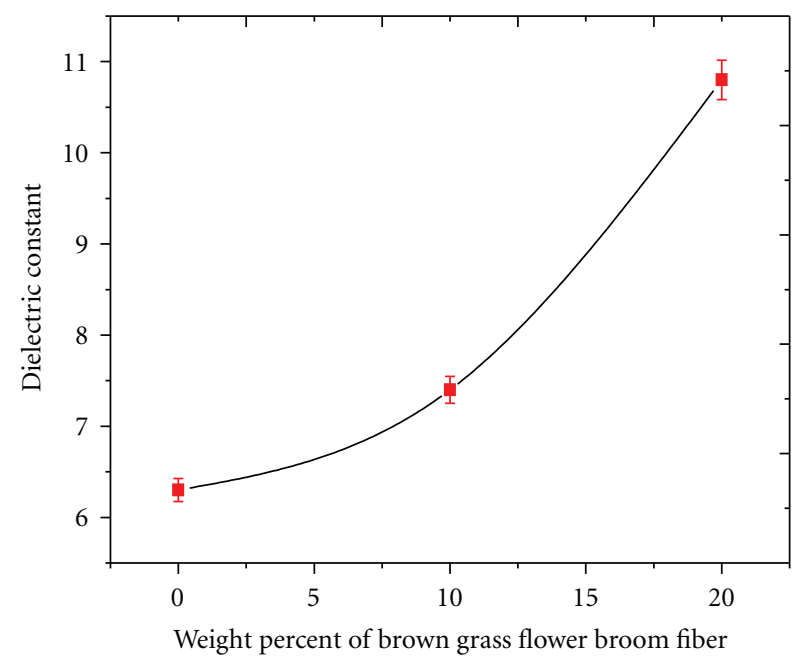

FIGURE 7: Variation of dielectric constant with amount of fibre reinforcement.

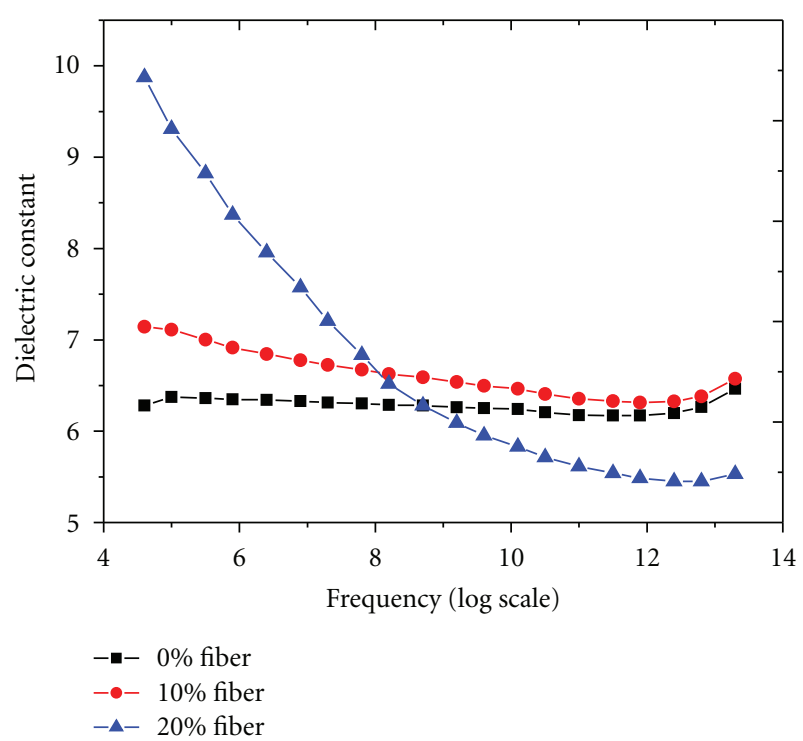

FIGURE 8: Variation of dielectric constant with frequency.

due to dielectric relaxation. From structural point of view, the dielectric relaxation involves oriental polarization which in turn depends on molecular arrangement of the dielectric material. At high frequency, the rotational motion of polar molecule is not sufficiently rapid for attainment of equilibrium with applied field, hence dielectric constant decreases. As the reinforcement content increases, the dielectric constant also increases. Dielectric loss of the composite shows a stabilizing trend with an increase in frequency which appears to be a beneficial from application point of view.

\section{Conclusions}

Brown grass flower broom fiber-reinforced epoxy composites can be prepared easily with different weight percentage of reinforcement. The polymer composite cost will be low as 


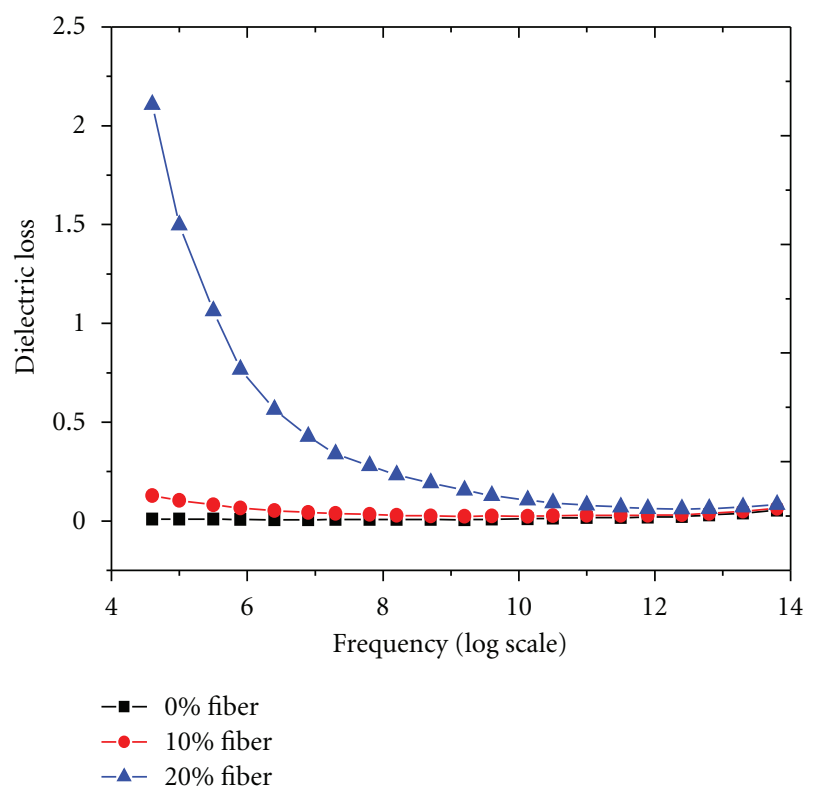

FIGURE 9: Variation of dielectric loss with frequency.

the raw material is plant fibre based, and the processing technique is simple. This composite has the lowest porosity and homogeneous surface structure, and a strong interface bonding of the broom fiber with epoxy resin is present. The void fraction of the composites increases slightly with the increase in the reinforcement content. It might be due to the presence of pores/cavities in the fibre. There is an increase in the flexural strength along with the increase in weight percent of short fiber flower broom in composites. Moreover the material is of light weight and possesses high strength. With the increase in reinforcement content, the density of the composite decreases, and the hardness of the composite increases, and hence make it of light weight and high of strength. Dielectric properties (relative permittivity and loss factor) of pure epoxy resin and composites with different amount of broom fiber-reinforced polymer composite have been studied in the frequency range from $100 \mathrm{~Hz}$ to $1 \mathrm{MHz}$. The experimental results indicate that the dielectric constant and dielectric loss factor decrease with the increasing frequency. It may/can be due to the orientation polarization, which has increased with increasing temperature, due to greater movement of polar molecular dipoles appears to be beneficial in electronic industry and can be processed by village artisans also. As the composite is made using bio-materials from local resources, its cost is less, compared to other polymer composites available today. This can further open up a new frontier for the industrialization at rural sectors.

\section{References}

[1] H. Peltola, B. Madsen, R. Joffe, and K. Nättinen, "Experimental study of fiber length and orientation in injection moulded natural fiber/starch acetate composites," Advances in Materials Science and Engineering, vol. 2011, Article ID 891940, 7 pages, 2011.
[2] M. H. Ab Ghani and S. Ahmad, "The comparison of water absorption analysis between counterrotating and corotating twin-screw extruders with different antioxidants content in wood plastic composites," Advances in Materials Science and Engineering, vol. 2011, Article ID 406284, 4 pages, 2011.

[3] A. Gupta, A. Kumar, A. Patnaik, and S. Biswas, "Effect of different parameters on mechanical and erosion wear behavior of bamboo fiber reinforced epoxy composites," International Journal of Polymer Science, vol. 2011, Article ID 592906, 10 pages, 2011.

[4] S. Kalia, L. Avérous, J. Njuguna, A. Dufresne, and B. M. Cherian, "Natural fibers, bio- and nanocomposites," International Journal of Polymer Science, vol. 2011, Article ID 735932, 2 pages, 2011.

[5] T. Williams, M. Hosur, M. Theodore, A. Netravali, V. Rangari, and S. Jeelani, "Time effects on morphology and bonding ability in mercerized natural fibers for composite reinforcement," International Journal of Polymer Science, vol. 2011, Article ID 192865, 9 pages, 2011.

[6] S. C. Mishra, "Low cost polymer composites with rural resources," Journal of Reinforced Plastics and Composites, vol. 28, no. 18, pp. 2183-2188, 2009.

[7] S. K. Acharya and S. C. Mishra, "Weathering behavior of flyash jute polymer composite," Journal of Reinforced Plastics and Composites, vol. 26, no. 12, pp. 1201-1210, 2007.

[8] J. George, M. S. Sreekala, and S. Thomas, "A review on interface modification and characterization of natural fiber reinforced plastic composites," Polymer Engineering and Science, vol. 41, no. 9, pp. 1471-1485, 2001.

[9] S. Varghese, B. Kuriakose, and S. Thomas, "Stress relaxation in short sisal-fiber-reinforced natural rubber composites," Journal of Applied Polymer Science, vol. 53, no. 8, pp. 1051-1060, 1994.

[10] Y. Mi, X. Chen, and Q. Guo, "Bamboo fiber-reinforced polypropylene composites: crystallization and interfacial morphology," Journal of Applied Polymer Science, vol. 64, no. 7, pp. 1267-1273, 1997.

[11] F. M. B. Coutinho, T. H. S. Costa, and D. L. Carvalho, "Polypropylene-wood fiber composites: effect of treatment and mixing conditions on mechanical properties," Journal of Applied Polymer Science, vol. 65, no. 6, pp. 1227-1235, 1997.

[12] H. K. Mishra and S. C. Mishra, "Erosion wear behaviour of coir dust reinforced polymer composite," Orissa Journal of Physics, vol. 18, no. 1, pp. 97-108, 2011.

[13] S. Joseph, M. S. Sreekala, Z. Oommen, P. Koshy, and S. Thomas, "A comparison of the mechanical properties of phenol formaldehyde composites reinforced with banana fibres and glass fibres," Composites Science and Technology, vol. 62, no. 14, pp. 1857-1868, 2002.

[14] N. Sombatsompop, K. Chaochanchaikul, C. Phromchirasuk, and S. Thongsang, "Effect of wood sawdust content on rheological and structural changes, and thermo-mechanical properties of PVC/sawdust composites," Polymer International, vol. 52, no. 12, pp. 1847-1855, 2003.

[15] H. Djidjelli, J. J. Martinez-Vega, J. Farenc, and D. Benachour, "Effect of wood flour content on the thermal, mechanical and dielectric properties of poly(vinyl chloride)," Macromolecular Material Engineering, vol. 287, no. 9, pp. 611-618, 2002.

[16] H. Djidjelli, M. Kaci, J. J. Martinez-Vega, and D. Benachour, "Effects of hydrothermal ageing on the thermal behaviour of poly(vinyl chloride) filled with wood flour," Polymer International, vol. 53, no. 11, pp. 1760-1765, 2004. 
[17] S. C. Mishra, N. B. Nayak, and A. Satapathy, "Investigation on bio-waste reinforced epoxy composites," Journal of Reinforced Plastics and Composites, vol. 29, no. 19, pp. 3016-3020, 2010.

[18] S. C. Mishra and H. Aireddy, "Evaluation of dielectric behavior of bio-waste reinforced polymer composite," Journal of Reinforced Plastics and Composites, vol. 30, no. 2, pp. 134-141, 2011.

[19] S. C. Mishra and N. B. Nayak, "An investigation of dielectric properties of chicken feather reinforced epoxy matrix composite," Journal of Reinforced Plastics and Composites, vol. 29, no. 17, pp. 2691-2697, 2010.

[20] A. Arbelaiz, B. Fernández, G. Cantero, R. Llano-Ponte, A. Valea, and I. Mondragon, "Mechanical properties of flax fibre/polypropylene composites. Influence of fibre/matrix modification and glass fibre hybridization," Composites Part A, vol. 36, no. 12, pp. 1637-1644, 2005. 

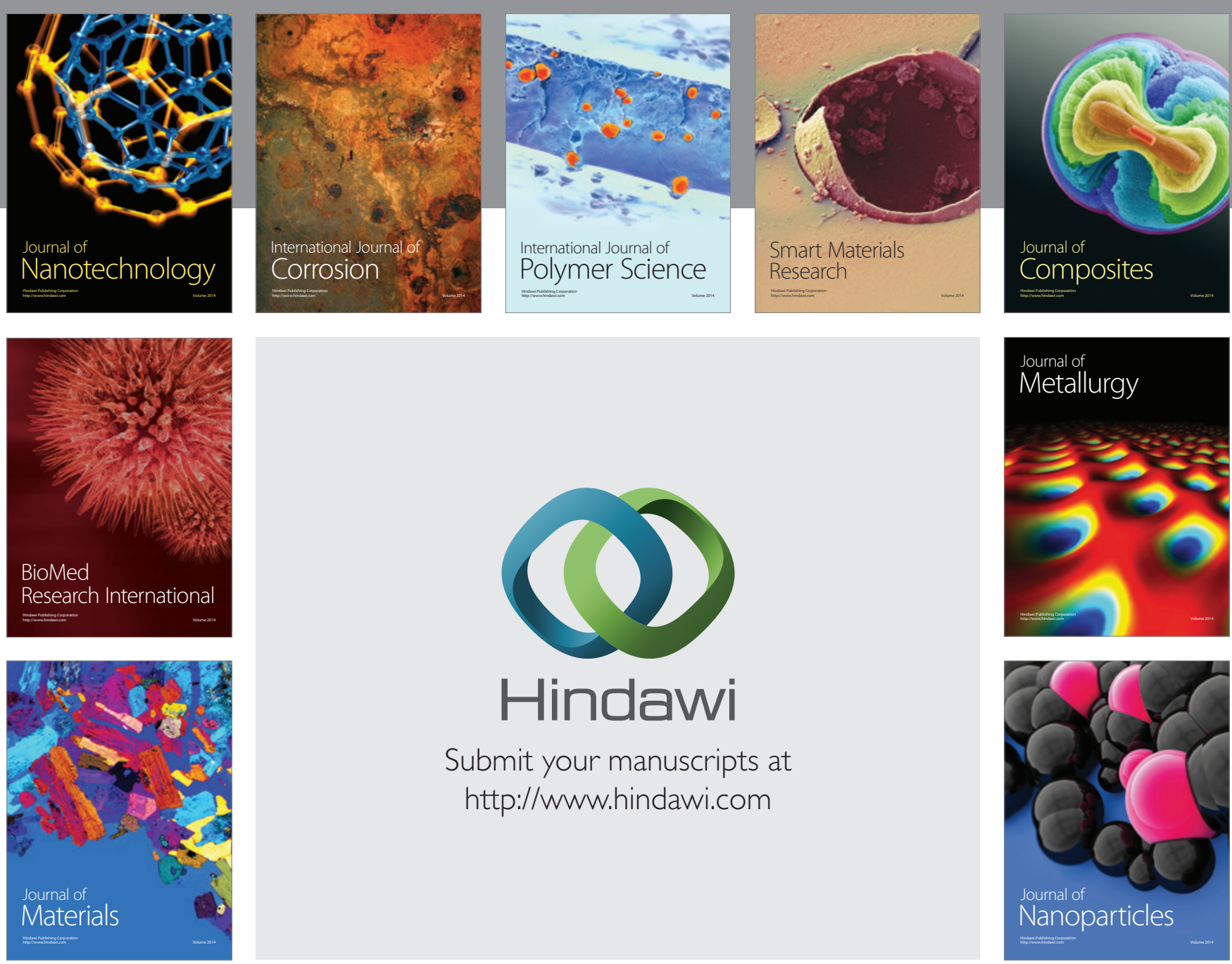

Submit your manuscripts at http://www.hindawi.com
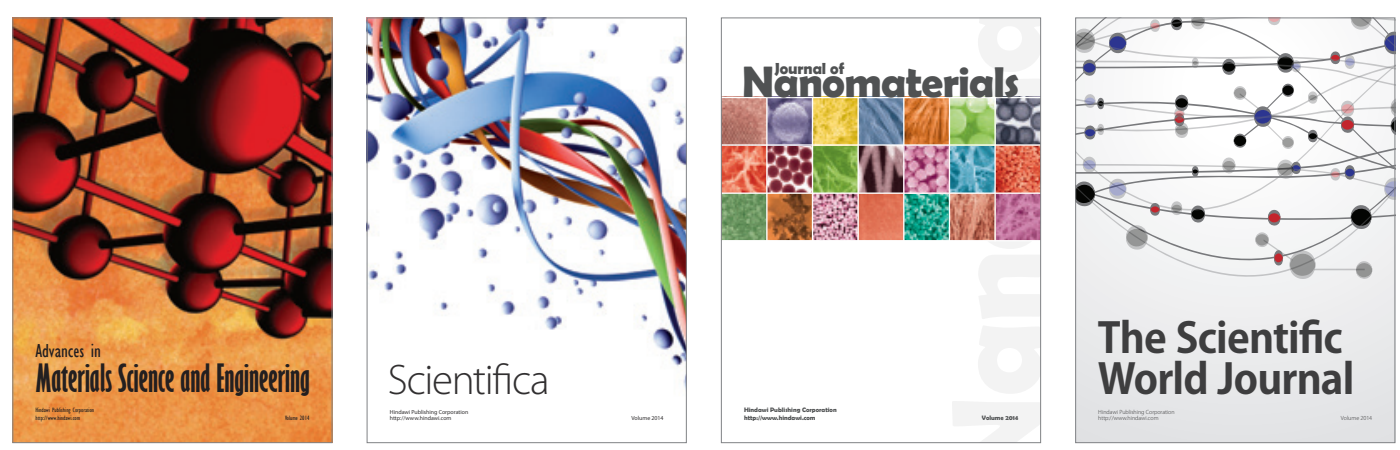

\section{The Scientific World Journal}
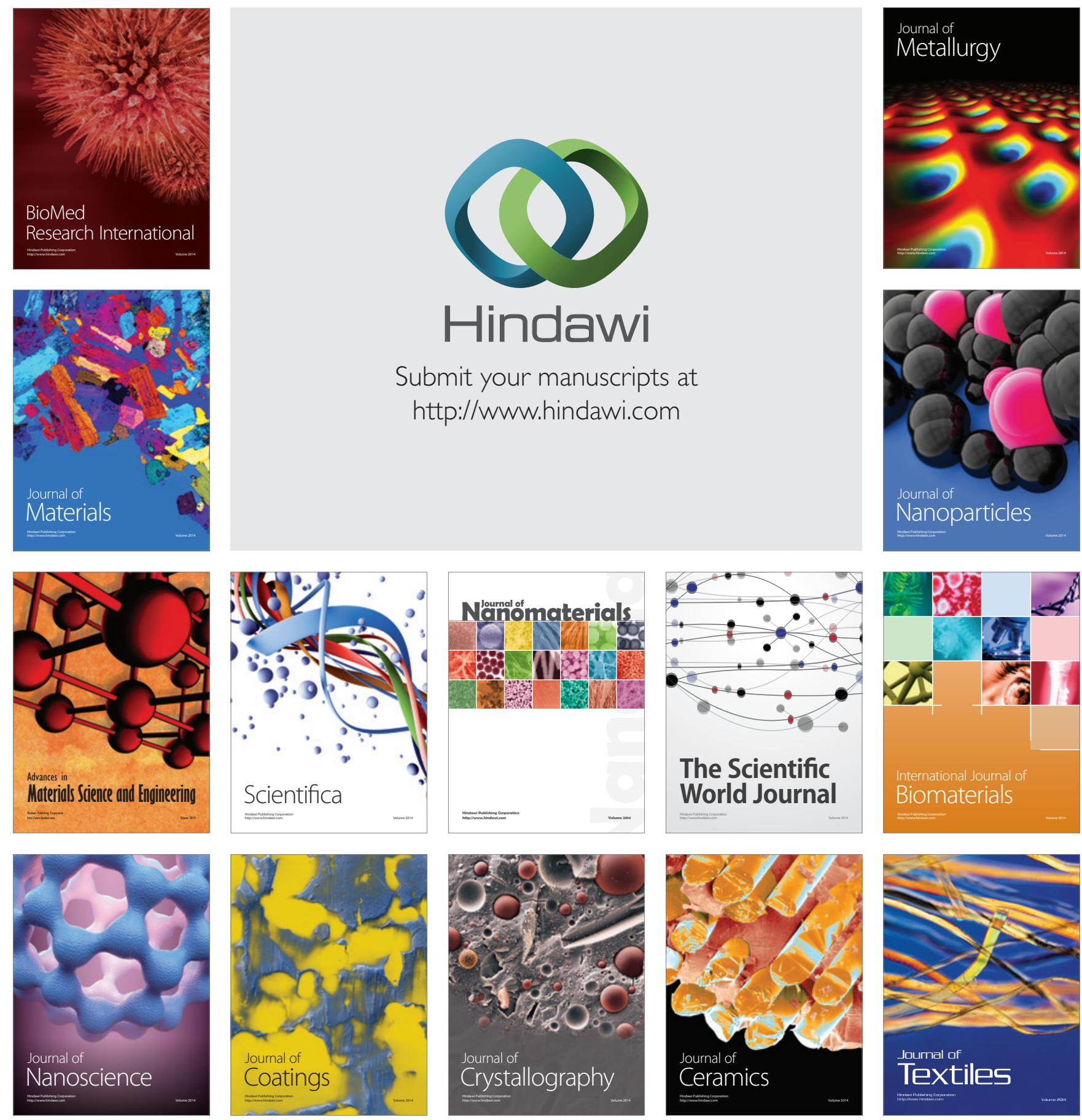